tant questions were identified that could be important to informing policy and promoting the transformation of struggling generalist practices into high performing, patient-centered primary care. Our authors are still working on synthesizing the feedback and prioritizing the questions. But a few examples include the following:

- What are the effects of using different definitions of the PCMH?

- What are the best measures that will be reflective of impact at the level of the practice and the community?

- What form should PCMH-based reimbursement incentives take, and how should these incentives be used for small practice settings?

- What form of support is most effective in promoting and sustaining practice transformation?

- How does the PCMH fit into the rest of the health care system?

The 6 key papers outlining the research agenda will be published in a special section of an upcoming issue of the Journal of General Internal Medicine. And we anticipate the sponsors of this process will be considering these findings as they establish future research priorities.

But these papers and the conference are only steps in the larger process of helping to make the $\mathrm{PCMH} \mathrm{a}$ reality. As these agendas are developed, it is essential for family medicine and our primary care colleagues to continue to be key leaders in this process. This will require engagement of academic family medicine organizations such as the Society of Teachers of Family Medicine (STFM), the North American Primary Care Research Group (NAPCRG), and the Council of Academic Family Medicine (CAFM). These organizations can work with AHRQ and with our colleagues in academic general internal medicine and academic pediatrics on developing a funded research agenda for the questions. More importantly, these academic organizations must work with our specialty organizations such as the American Academy of Family Physicians, to help determine how to make the $\mathrm{PCMH}$ a reality in clinical practice. This requires the involvement of practicing physicians to help determine which questions are most important to answer to assist in the development of PCMHs. It requires dissemination of these answers to practicing physicians as this new knowledge is generated. It requires engagment with patients and families to ensure that the model is truly patient-centered and family-centered. And it requires collaboration with payers and policy makers to implement payment policies that can support the PCMH model.

This collaborative project of the primary care organizations reflects one step in generating and dissemi- nating the knowledge needed to help make the PCMH a reality.

James M. Gill, MD, MPH

Delaware Valley Outcome Research and Jefferson Medical College Bruce E. Landon, MD, MBA

Harvard Medical School and Betb Israel Deaconess Medical Center Richard C. Antonelli, MD, MS

Harvard Medical School and Children's Hospital Boston

Eugene C. Rich, MD

Creighton University School of Medicine



Ann Fam Med 2010;8:89-90. doi:10.1370/afm.1085.

\section{ALLIES IN FAMILY MEDICINE ADVOCACY: THE PATIENT-CENTERED PRIMARY CARE COLLABORATIVE}

In the quest for better health care for all Americans, the discipline of family medicine needs influential, aggressive allies. For decades, academic and organized medicine, the government, insurers, and consumers of health care have shown little interest in the development of an effective, efficient, and equitable health care system.

In 2005, IBM recognized that the health care it purchased was costly and of poor quality, mainly because there were no incentives for the provision of continuous, longitudinal care. In 2006, large employers led by IBM organized a coalition of consumer groups, quality organizations, health plans, labor unions, and physician groups to advance the principles of the PatientCentered Medical Home (PCMH) and advocate for a model of health care compensation with the appropriate incentives. This coalition was named the Patient-Centered Primary Care Collaborative (PCPCC).

ADFM has joined the AAFP and the other members of the PCPCC, who are united in the belief that primary care is the foundation of a high performing health care system and that the PCMH is the key organizational construct to improve care coordination, advance the meaningful use of electronic health records, enhance access, and simultaneously improve outcomes and lower costs. ADFM holds positions on the advisory and legislative committees of the PCPCC.

The PCPCC is an important ally in our advocacy efforts. A recent example of the collaborative efforts is a letter sent to the members of the Senate. The mem- 
bers of the PCPCC were encouraged that the Senate health reform bills reported out of the Finance Committee and the Committee on Health Education Labor and Pensions (HELP) include these provisions that emphasize a foundation of primary care:

1. A Medicaid state plan option in which enrollees with at least 2 chronic conditions can designate a primary care provider in a $\mathrm{PCMH}$

2. A CMS Innovation Center authorized to test, evaluate, and expand new payment structures that will foster patient-centered care, improve quality, and slow the rate of Medicare cost increase

3. A $10 \%$ bonus for primary care practitioners

4. Medicare direct and indirect Graduate Medical Education funding for Teaching Health Centers (ie, GME funding that is paid directly to nonhospital entities to foster education in outpatient and community venues)

The PCPCC was concerned that the bills included only high-need, high-cost patients and ignored the fact that the entire population is benefited by access to primary care. In an excerpt from the letter, the Senators were reminded that:

"a guiding principle of the PCMH is that comprehensive, continuous, coordinated and preventive care, managed by a highly trained clinician in a transformed practice, can prevent complications that could result in a patient becoming high-need or high-cost. If Congress' goal is to improve outcomes, lower costs, and prevent disease and complications associated with chronic illnesses, as it must be, it would be a missed opportunity to limit PCMH eligibility. In addition, practices are much more likely to make the investment in practice transformation to become PCMHs if many of their patients are eligible to participate and they will receive care coordination payments for such patients. Furthermore, we have concerns about the feasibility and unintended administrative burden of practices identifying those patients".

The PCPCC recommended that:

1. The Medicare and Medicaid pilots should be broadly inclusive of all patients who will benefit from preventive and coordinated care and not be restricted to "high-cost" or "high-needs" patients

2. Payment models should recognize differences among the patient populations and the differing needs of care or care coordination

3. Payment models should include both private and public payers to maximize the impact of the pilot programs for a majority of patients in a practice

If health and health care in the United States are to be improved, the clear and powerful voice of a unified coalition must articulate the evidence of effectiveness, the expectation for transformation, and the vision for innovation. The PCPCC has begun this foundational work and the voice needs to grow louder. The PCPCC will be most effective when members spur their constituencies to action. Departments of family medicine must not only encourage our own faculties, but must also energize medical schools and academic health centers to join the movement to build a more effective coalition for systemic change. ADFM is forming a taskforce to help coordinate this forward movement within our own organization. We encourage all of the organizations of the family to become engaged with us.

This commentary was written by members of the ADFM Legislative Affairs Committee, with review and comment from the ADFM Executive Committee Mary Nolan Hall, MD Jerry Kruse, MD, MSPH and the Association of Departments of Family Medicine

\section{References}

1. Patient-Centered Primary Care Collaborative. Sign-on letter to Senate regarding the role of the $\mathrm{PCMH}$ in health care reform. http:// pcpcc.net/content/sign-letter-senate-regarding-role-pcmh-healthcare-reform-3.

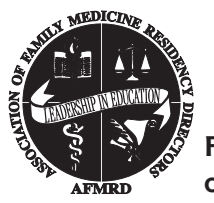

From the Association of Family Medicine Residency Directors

Ann Fam Med 2010; 8:90-91. doi:10.1370/afm.1088.

\section{AFMRD-IMPROVING CONTINUITY OF COMMUNICATION}

Program directors (PDs) and faculty deal with issues of ensuring and enhancing patient continuity of care by residents. In much the same way, the AFMRD strives to keep members informed and up to date on topics of common interest.

Silence may be golden, but open, honest, and interactive communication is pure gold. One of the board's tasks is to improve continuity of communication with our members. This is the responsibility of the AFMRD Communication Committee.

Ascertaining the questions and concerns of our over 450 PDs, located in geographically diverse locations and working in a multitude of different practices, is a monumental task. Questions arise on a daily basis for PDs and family medicine faculty. To whom should the question be directed? Who is a recognized content expert?

Many questions are posted on our AFMRD program director list serve. The traffic can be heavy and often redundant. Senior directors recognize that there 